\title{
Effect of Cu-Addition and Die-Upset Temperature on Texture in Die-Upset Nd-Lean Nd-Fe-B Alloys
}

\author{
H. W. Kwon ${ }^{1 *}$ and J. H. Yu ${ }^{2}$ \\ ${ }^{1}$ Pukyong National University, Busan 608-739, Korea \\ ${ }^{2}$ Korea Institute of Materials Science, Changwon, Gyeongnam 641-831, Korea
}

(Received 19 February 2010, Received in final form 10 March 2010, Accepted 11 March 2010)

\begin{abstract}
The effects of $\mathrm{Cu}$-addition and die-upset temperature on the texture in the die-upset $\mathrm{Nd}$-lean $\mathrm{Nd}_{\mathbf{x}} \mathrm{Fe}_{93.5-(\mathrm{x}+\mathrm{y})^{-}}$ $\mathrm{Cu}_{\mathrm{y}} \mathrm{Ga}_{0.5} \mathrm{~B}_{6}(\mathrm{x}=\mathbf{9 - 1 2}, \mathrm{y}=\mathbf{0 - 2})$ alloys were investigated. The die-upset $\mathrm{Cu}$-containing $\mathrm{Nd}$-lean $\mathrm{Nd}_{12} \mathrm{Fe}_{81.5-\mathrm{y}^{-}}$ $\mathrm{Cu}_{\mathrm{y}} \mathrm{Ga}_{0.5} \mathrm{~B}_{6}(\mathrm{y}=1,2)$ alloys showed a considerable texture. Texture in the Nd-lean alloys developed through basal plane slip deformation. The $\mathrm{Cu}$-addition reduced the melting point of grain boundary phase facilitating grain gliding during the die-upsetting, and providing a greater chance for the $\mathrm{Nd}_{2} \mathrm{Fe}_{14} \mathrm{~B}$ grains to meet the deformation conditions. Die-upsetting at higher temperature facilitated grain gliding and plastic deformation, thus enhancing texture.
\end{abstract}

Keywords: permanent magnets, $\mathrm{Nd}-\mathrm{Fe}-\mathrm{B}$, texture, die-upset

\section{Introduction}

Die-upsetting is a unique process by which the hard magnetic $\mathrm{Nd}_{2} \mathrm{Fe}_{14} \mathrm{~B}$ grains in a melt-spun Nd-Fe-B alloy are aligned by simple deformation at an elevated temperature. The likelihood of texture formation by die-upset is heavily dependent upon alloy composition, particularly the Nd-content. Thus far, for an Nd-rich Nd-Fe-B alloy with an Nd-content well over the $\mathrm{Nd}_{2} \mathrm{Fe}_{14} \mathrm{~B}$ stoichiometric composition (11.8 at\%), the die-upset induced a good texture. However, for an Nd-lean Nd-Fe-B alloy with an $\mathrm{Nd}$-content near or under the $\mathrm{Nd}_{2} \mathrm{Fe}_{14} \mathrm{~B}$ stoichiometric composition, die-upset only led to a poor texture. The good texture in the die-upset Nd-rich alloy was closely related to the presence of an abundant Nd-rich grain boundary phase, which is liquid during die-upsetting. The texture in the Nd-rich alloy develops by taking advantage of the liquid via a stress-induced preferential grain growth mechanism [1-3]. Meanwhile, the Nd-lean alloys bear little to no Nd-rich grain boundary phase, and thus it would seem natural that in the Nd-lean alloys a good texture cannot be achieved by the die-upset. However, an appreciable texture has recently been achieved in a dieupset Nd-lean alloy [4-6]. In the present study, the effects of $\mathrm{Cu}$-addition and die-upset temperature upon the texture of the die-upset Nd-lean Nd-Fe-B alloys were investigated.

\section{Experimental Work}

The $\mathrm{Nd}_{\mathrm{x}} \mathrm{Fe}_{93.5-(\mathrm{x}+\mathrm{y})} \mathrm{Cu}_{\mathrm{y}} \mathrm{Ga}_{0.5} \mathrm{~B}_{6}(\mathrm{x}=9-12, \mathrm{y}=0-2)$ starting alloys were melt-spun, and the obtained ribbon briefly milled. The milled powder was then hot-pressed at 750 ${ }^{\circ} \mathrm{C}$, and subsequently die-upset at various temperatures ranging from 750 to $900{ }^{\circ} \mathrm{C}$ to achieve an approximate $75 \%$ height reduction. Process details of the hot-pressing and die-upsetting have been previously published [7]. Texture in the die-upset magnets was evaluated by the ratio of $\mathrm{M}_{7(/)} / \mathrm{M}_{7(\perp)}$, where, $\mathrm{M}_{7(/)}$ and $\mathrm{M}_{7(\perp)}$ are the magnetization at $7 \mathrm{kOe}$ in the first quadrant of the demagnetisation curve parallel and perpendicular to the pressing direction. The demagnetisation curves (corrected using a demagnetising factor of 0.33 ) were measured using VSM at room temperature after pre-magnetizing with a $50 \mathrm{kOe}$ pulsing field. Differential thermal analysis (DTA) was performed in Ar gas using the hot-pressed sample (100 $\mathrm{mg}$ ). The microstructure of the die-upset sample was examined by observing the fracture surface of the sample using SEM after brief cracking. 


\section{Results and Discussion}

Fig. 1 shows the demagnetisation curves of the dieupset Nd-lean alloys $\left(\mathrm{Nd}_{12} \mathrm{Fe}_{81.5} \mathrm{Ga}_{0.5} \mathrm{~B}_{6}\right.$ and $\mathrm{Nd}_{9} \mathrm{Fe}_{84.5^{-}}$ $\mathrm{Ga}_{0.5} \mathrm{~B}_{6}$ ) measured parallel and perpendicular to the pressing direction. The Nd-lean alloys die-upset at $750^{\circ} \mathrm{C}$ showed poor texture. The poor texture was not improved even at higher temperature as shown in Fig. 2. The grain shape in the die-upset sample evidenced the poor texture. As shown in Fig. 3, the grains were in equi-axed shape, with no grain texture observed. The negligible texture in these Nd-lean alloys was attributed primarily to the lack of an Nd-rich grain boundary phase. Fig. 4 shows the DTA results of the hot-pressed Nd-Fe-B alloys with different compositions. The endothermic event around $650{ }^{\circ} \mathrm{C}$ corresponded to the melting of the Nd-rich grain boundary phase in the alloys. No endothermic event for the alloy with an Nd-content of 9 at $\%$ indicated an absence of the grain boundary phase (Fig. 4(a)). Although some grain boundary phase existed in the alloy with a 12

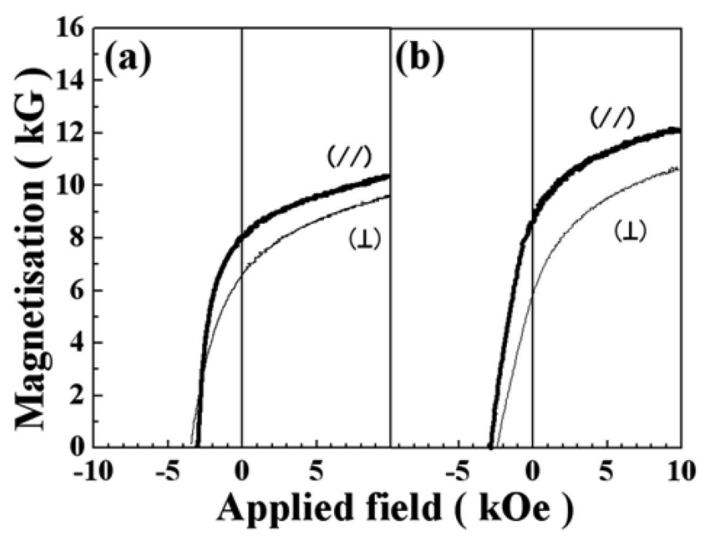

Fig. 1. Demagnetisation curves of the (a) $\mathrm{Nd}_{12} \mathrm{Fe}_{81.5} \mathrm{Ga}_{0.5} \mathrm{~B}_{6}$ and (b) $\mathrm{Nd}_{9} \mathrm{Fe}_{84.5} \mathrm{Ga}_{0.5} \mathrm{~B}_{6}$ alloys die-upset at $750{ }^{\circ} \mathrm{C}$.

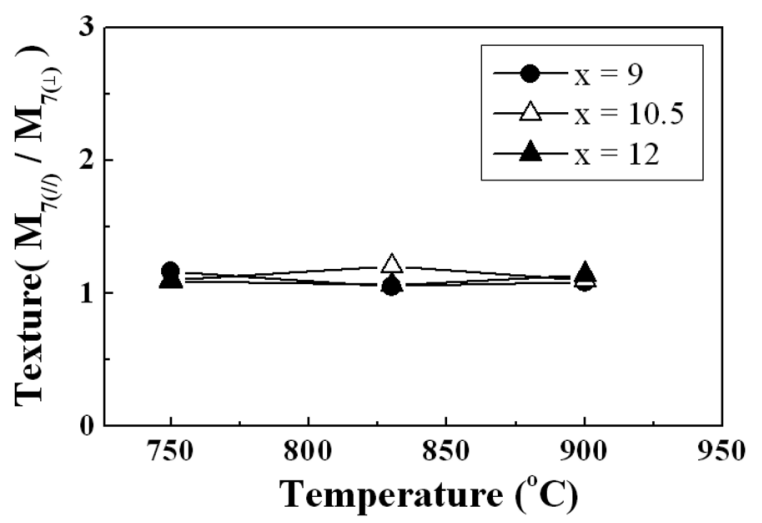

Fig. 2. Effect of die-upset temperatures on the texture of the die-upset $\mathrm{Nd}_{\mathrm{x}} \mathrm{Fe}_{93.5-\mathrm{x}} \mathrm{Ga}_{0.5} \mathrm{~B}_{6}$ alloys.

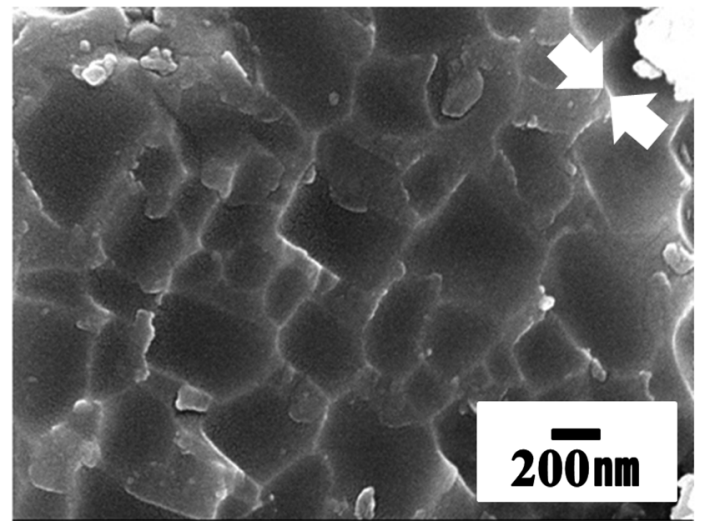

Fig. 3. SEM images showing the fracture surface of the $\mathrm{Nd}_{12} \mathrm{Fe}_{81.5} \mathrm{Ga}_{0.5} \mathrm{~B}_{6}$ alloys die-upset at $830^{\circ} \mathrm{C}$ (Arrows indicate pressing direction).

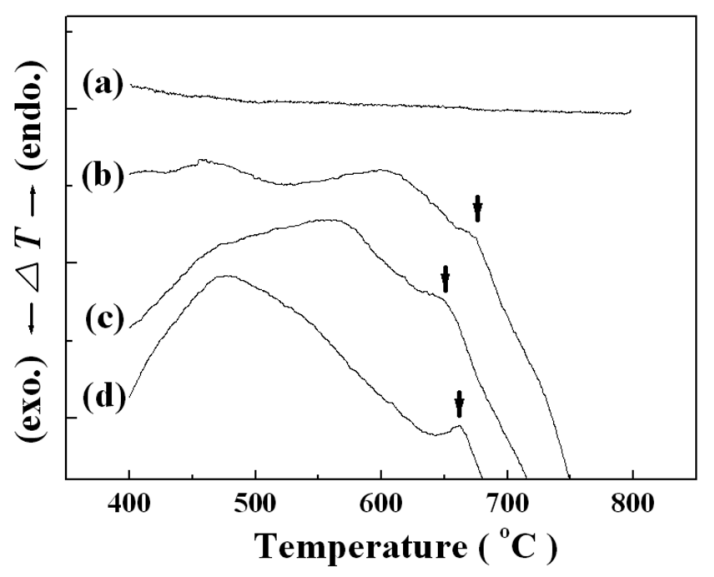

Fig. 4. DTA results on the hot-pressed compact of the (a) $\mathrm{Nd}_{9} \mathrm{Fe}_{84.5} \mathrm{Ga}_{0.5} \mathrm{~B}_{6}$, (b) $\mathrm{Nd}_{12} \mathrm{Fe}_{81.5} \mathrm{Ga}_{0.5} \mathrm{~B}_{6}$, (c) $\mathrm{Nd}_{12} \mathrm{Fe}_{79.5} \mathrm{Cu}_{2} \mathrm{Ga}_{0.5^{-}}$ $\mathrm{B}_{6}$, and (d) $\mathrm{Nd}_{13.5} \mathrm{Fe}_{80} \mathrm{Ga}_{0.5} \mathrm{~B}_{6}$ alloy.

at $\%$ Nd-content (Fig. 4(b)), it was much smaller compared to that for the Nd-rich alloy with a 13.5 at $\%$ Ndcontent (Fig. 4(d)). Development of a texture in a dieupset Nd-Fe-B alloy was closely related to the Nd-rich grain boundary phase. The Nd-rich alloy $(13.5 \mathrm{at} \% \mathrm{Nd})$ had a typical composition with good texture after the dieupset. This Nd-rich alloy inherently contained a considerable amount of Nd-rich grain boundary phase, became liquid during the die-upset. In the Nd-rich alloy, the texture developed via a stress-induced preferential growth of the $\mathrm{Nd}_{2} \mathrm{Fe}_{14} \mathrm{~B}$ grain by taking advantage of the abundant liquid grain boundary phase [1-3]. During the dieupsetting, unfavourable grains, of which the c-axis is out of the pressing direction, are dissolved into the liquid grain boundary phase and precipitated preferentially on the lateral surface of the favourable grains, of which the $\mathrm{c}$-axis is parallel to the pressing direction. The Nd-lean alloys studied herein bore little grain boundary phase, 


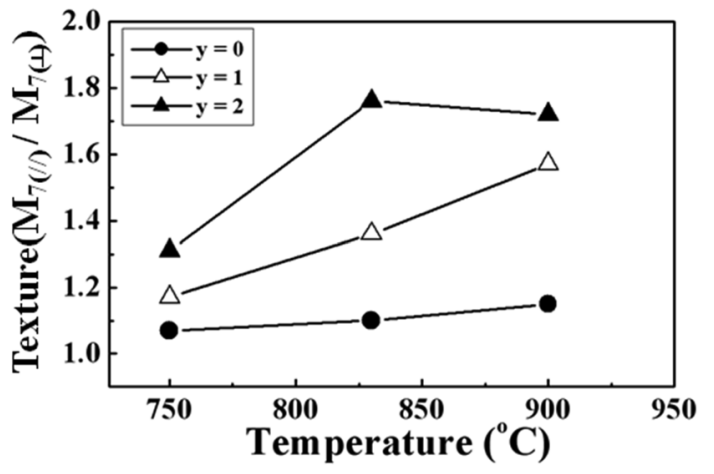

Fig. 5. Effect of $\mathrm{Cu}$-addition and die-upset temperatures on the texture of $\mathrm{Nd}_{12} \mathrm{Fe}_{81.5-\mathrm{y}} \mathrm{Cu}_{\mathrm{y}} \mathrm{Ga}_{0.5} \mathrm{~B}_{6}$ alloys.

thus the stress-induced preferential grain growth could not operate.

Fig. 5 shows the effects of $\mathrm{Cu}$-addition and die-upset temperature upon the texture in the Nd-lean $\mathrm{Nd}_{12} \mathrm{Fe}_{81.5-\mathrm{y}^{-}}$ $\mathrm{Cu}_{\mathrm{y}} \mathrm{Ga}_{0.5} \mathrm{~B}_{6}$ alloys. The $\mathrm{Cu}$-containing alloys showed textures in the samples die-upset at $750^{\circ} \mathrm{C}$ much higher than the alloy without $\mathrm{Cu}$. Moreover, unlike the alloy without $\mathrm{Cu}$ the $\mathrm{Cu}$-containing alloys showed much improved texture when die-upset at higher temperatures. The induced texture in the $\mathrm{Cu}$-added alloy was evidenced by the morphology of the grains in the sample die-upset at higher temperatures. As shown in Fig. 6(a), the grains in the $\mathrm{Cu}-$ added sample had a texture, whereby the grains were

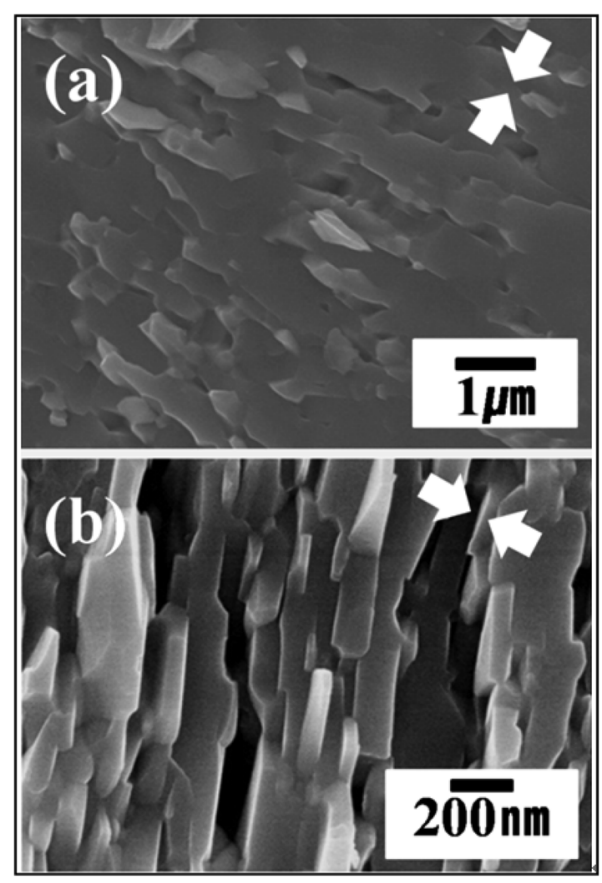

Fig. 6. SEM images showing the fracture surface of the (a) $\mathrm{Nd}_{12} \mathrm{Fe}_{79.5} \mathrm{Cu}_{2} \mathrm{Ga}_{0.5} \mathrm{~B}_{6}$ alloy die-upset at $900{ }^{\circ} \mathrm{C}$, and (b) $\mathrm{Nd}_{13.5^{-}}$ $\mathrm{Fe}_{80} \mathrm{Ga}_{0.5} \mathrm{~B}_{6}$ alloy die-upset at $750{ }^{\circ} \mathrm{C}$. elongated and the long axis aligned perpendicular to the pressing direction. The texture in the $\mathrm{Cu}$-containing $\mathrm{Nd}-$ lean alloy seems to have been induced by a slight enrichment of the grain boundary phase due to the $\mathrm{Cu}$-addition. However, the DTA results showed that the increase in the amount of grain boundary phase by $\mathrm{Cu}$-addition was insignificant (Fig. 4(b) and 4(c)). The lack of a grain boundary phase in the $\mathrm{Cu}$-containing Nd-lean alloy could also be evidenced by the fracture surface morphology of the die-upset sample. In the Cu-added Nd-lean alloy the fracture generally occurred in a trans-granular mode (Fig. 6(a)), and this fracture mode was radically different from that in the Nd-rich alloy, in which the fracture occurred in an inter-granular mode along the abundant grain boundary (Fig. 6(b)). The trans-granular fracture in the $\mathrm{Cu}$-added Nd-lean alloy indicated a lack of the grain boundary phase. Although the $\mathrm{Cu}$-addition caused insignificant enrichment of the grain boundary phase, a considerable texture developed in the $\mathrm{Cu}$-added alloys, indicating that the texture in the $\mathrm{Cu}$-added Nd-lean alloy developed by a mechanism different from the stress-induced preferential grain growth operating in the Nd-rich alloy. Decisive evidence for a different texture formation mechanism in the $\mathrm{Cu}$-added Nd-lean alloy was found in the temperature dependence of the texture. When the texture in a dieupset Nd-Fe-B alloy developed via the stress-induced preferential grain growth of crystallographically favourable grains, it usually decreased with increasing die-upset temperature [7]. In the present case, however, the reverse was true, in which the texture increased with increasing die-upset temperature. The texture in a die-upset Nd-lean alloy is known to develop by a basal plane slip deformation mechanism [7]. In this mechanism an easy grain boundary gliding during the die-upsetting facilitates texture inducement. As seen in Fig. 4(c), the Cu-addition significantly reduced the melting point of the grain boundary phase (from 680 to $650^{\circ} \mathrm{C}$ approximately). A previous study reported that the $\mathrm{Cu}$ atoms added to the $\mathrm{Nd}-\mathrm{Fe}-\mathrm{B}$ alloy primarily segregated at the grain boundaries rather than dissolved into the $\mathrm{Nd}_{2} \mathrm{Fe}_{14} \mathrm{~B}$ matrix grains [8]. The melted grain boundary region probably possessed higher fluidity, thus providing better lubrication, and facilitating grain gliding during die-upsetting. Therefore, more grains may have a chance where the magnitude of the resolved shear stresses along the basal plane reaches a critical value for plastic deformation. This effect may become more profound as the die-upset temperature increases because the lubrication of the grain boundary is enhanced. Simultaneously, the critical value for the slip deformation is reduced at higher die-upset temperatures and the $\mathrm{Nd}_{2} \mathrm{Fe}_{14} \mathrm{~B}$ grains deform more readily. These two 
factors of the $\mathrm{Cu}$-addition and higher die-upset temperatures may possess synergy sufficient for inducing a texture in the die-upset Nd-lean Nd-Fe-B alloys.

\section{Conclusion}

A considerable texture was developed in the die-upset Nd-lean $\mathrm{Nd}_{12} \mathrm{Fe}_{81.5-\mathrm{y}} \mathrm{Cu}_{\mathrm{y}} \mathrm{Ga}_{0.5} \mathrm{~B}_{6}(\mathrm{y}=1,2)$ alloys through basal plane slip deformation. The $\mathrm{Cu}$-addition to the $\mathrm{Nd}$ lean Nd-Fe-Ga-B alloys significantly reduced the melting point of the grain boundary phase, facilitating grain gliding during the die-upsetting, more grains thus have a chance where the magnitude of the resolved shear stresses along the basal plane reach a critical value for plastic deformation. At higher die-upset temperatures grain gliding and plastic deformation were enhanced. Accordingly, this could come in to play for texture improvement.

\section{Acknowledgement}

The present work was supported by a grant from the Fundamental R\&D Program for Core Technology of
Materials funded by the Ministry of Knowledge Economy, Republic of Korea.

\section{References}

[1] R. K. Mishra, E. G. Brewer, and R. W. Lee, J. Appl. Phys. 63, 3528 (1988).

[2] L. Li and C. D. Graham Jr., J. Appl. Phys. 67, 4756 (1990).

[3] L. Li, and C. D. Graham Jr., IEEE Trans. Magn. 28, 2130 (1992).

[4] A. M. Gabay, Y. Zhang, and G. C. Hadjipanayis, J. Magn. Magn. Mater. 294, 287 (2005).

[5] A. M. Gabay, Y. Zhang, and G. C. Hadjipanayis, J. Magn. Magn. Mater. 302, 244 (2006).

[6] G. C. Hadjipanayis, J. F. Liu, A. M. Gabay, and M. Marinescu, Proc. 19th International Workshop on Rare Earth Permanent Magnets and Their Applications, Beijing, China, Vol. I, 12 (2006).

[7] H. W. Kwon and J. H. Yu, IEEE Trans. Magn. 45, 4435 (2009).

[8] L. F. C. P. Lima, H. Takiish, and R. N. Faria, J. Magn. Magn. Mater. 285, 112 (2005). 